\title{
A IMPORTÂNCIA DO USO DO MAPA NO ENSINO REMOTO PARA APRENDIZAGEM DE GEOGRAFIA
}

\section{ARTIGO DE REVISÃo}

SILVA, Raimunda de Carvalho ${ }^{1}$

SILVA, Raimunda de Carvalho. A importância do uso do mapa no ensino remoto para aprendizagem de geografia. Revista Científica Multidisciplinar Núcleo do Conhecimento. Ano 06, Ed. 06, Vol. 09, pp. 137-154. Junho de 2021. ISSN: 24480959, Link de acesso:

https://www.nucleodoconhecimento.com.br/educacao/aprendizagem-de-geografia, DOI: 10.32749/nucleodoconhecimento.com.br/educacao/aprendizagem-de-geografia

\section{RESUMO}

No atual cenário mundial, promovido pelas consequências da pandemia da COVID19, o professor vem enfrentando vários desafios. Nesse contexto, é necessário discutirmos sobre novas perspectivas para educação, visando a utilização de instrumentos facilitadores para o processo ensino e aprendizagem, alinhados à modalidade do ensino remoto. Este trabalho tem como objetivo discutir acerca da importância do uso do mapa para o ensino de Geografia e a importância de sua utilização através do ensino remoto. Para tanto a discussão proposta neste trabalho, partiu de leitura bibliográfica e das dificuldades vivenciadas a partir de experiências pessoais da autora, relacionadas ao ensino de Geografia com a utilização do mapa em aulas remotas durante a pandemia. Concluiu-se diante do que foi discutido ao longo deste trabalho, que se faz necessário, o uso do mapa através do ensino remoto, como instrumento facilitador da aprendizagem do conteúdo geográfico, para que ocorra a formação dos alunos, visando prepará-los para a leitura e

\footnotetext{
${ }^{1}$ Mestranda em Ciências da Educação; Especialista em Metodologia do Ensino na Educação Básica; Graduada em Geografia.
}

RC: 88698

Disponível em: https://www.nucleodoconhecimento.com.br/educacao/aprendizagemde-geografia 
compreensão de espaço, auxiliando no entendimento dos acontecimentos ao seu redor e da realidade na qual estão inseridos.

Palavras-chave: mapa, ensino, aprendizagem, geografia.

\section{INTRODUÇÃO}

O ano de 2020 foi difícil para os professores em função da COVID-19. A sobrecarga, o cansaço e principalmente, a falta de motivação, associada ao medo, contribuíram para o surgimento de um novo perfil profissional para a educação. Os professores precisaram se adaptar a um modelo de ensino pautado na nova realidade, em virtude da pandemia. Nesse cenário, o ensino não poderia ser como antes, mas com novas propostas metodológicas para a aprendizagem.

Diante do exposto, a educação a distância assume o papel principal por conta das restrições impostas pela pandemia. Nesse sentido, os professores precisaram estudar, assistir tutoriais na internet e tentar de várias maneiras superar as dificuldades em relação ao uso das tecnologias. Para os professores de Geografia, surgiram novos desafios: como trabalhar a leitura e interpretação do mapa, associado ao conteúdo geográfico de forma remota? E quais possibilidades de aprendizagem nessa modalidade de ensino?

A intenção desse trabalho não é responder a todas estas perguntas, mas promover uma reflexão sobre o uso do mapa em aulas de Geografia de forma remota e sua contribuição para o processo ensino e aprendizagem, posto que o mapa sempre esteve presente nos livros didáticos de Geografia, sendo as vezes ignorado por muitos professores, principalmente no Ensino Fundamental.

Por ser um instrumento de grande relevância para aprendizagem dos conteúdos geográficos, tornou-se indispensável sua utilização como recurso didático e, trabalhar com mapas de forma remota, apesar dos esforços, ainda é um grande

RC: 88698

Disponível em: https://www.nucleodoconhecimento.com.br/educacao/aprendizagem- 
desafio para os professores de Geografia. Portanto, sobre este aspecto, o objetivo principal aqui é discutir a importância da utilização do mapa como instrumento metodológico, através do ensino remoto para compreensão dos conteúdos geográficos.

A leitura de mapas, não é tão simples, embora seja uma atividade muitas vezes divertida, porque pode ser desenvolvida de várias maneiras, tornando-se um instrumento lúdico, no entanto, esse processo se torna mais complexo a distância e, principalmente se o professor e o aluno não têm domínio dessa linguagem, entretanto, sua utilização é necessária para que o aluno compreenda o conteúdo da Geografia, principalmente através do ensino remoto.

Ao se apropriar do conhecimento cartográfico, o educando interpretará códigos e símbolos existentes no mapa, contribuindo para o entendimento do espaço geográfico e sua produção a partir da ação do homem. Com esse entendimento, o aluno fará uma análise crítica dos acontecimentos, da produção dos lugares, dos conflitos existentes no mundo, dos fenômenos atmosféricos, bem como da realidade na qual está inserido, contribuindo para sua orientação no espaço, sua autonomia e reflexão consciente de sua participação no processo de construção social.

Diante disso, é de suma importância considerar o mapa como instrumento pedagógico indispensável para o ensino de Geografia, inclusive, de forma remota, pois os mesmos estão presentes nos livros didáticos como ferramenta pedagógica direcionada a compreensão do conteúdo e não somente de Geografia, mas de outras áreas do conhecimento.

O presente estudo, propõe uma análise discursiva sobre a importância da utilização do mapa para o ensino de Geografia de forma remota, com base em conceitos, conteúdos e métodos, pautado em estudos bibliográficos. Para tanto, considerou-se alguns autores como Castellar (2017); Cavalcanti (2017); Callai (2017); Martinelli (2017); Almeida (2018), Simielli (2018), Castrogiovanni (2017), entre outros, que

RC: 88698

Disponível em: https://www.nucleodoconhecimento.com.br/educacao/aprendizagem- 
consideram o mapa um instrumento de suma importância para compreensão do conteúdo geográfico.

Não vamos tratar aqui, do mapa apenas como instrumento pedagógico, mas de sua importância para o entendimento dos conteúdos geográficos, para a resolução de problemas da vida cotidiana. Não deve haver, portanto, o ensino de Geografia sem a compreensão da linguagem cartográfica, pois não havendo o domínio da simbologia do mapa, dificulta a aprendizagem e torna o ensino meramente tradicional e sem valor social para o educando.

A leitura de textos sem nenhuma compreensão faz com que o verdadeiro significado do ensino de Geografia não contemple a sociedade. A deficiência de muitos alunos em relação ao domínio da linguagem cartográfica contribui para a formação de adultos analfabetos cartograficamente, por conseguinte, pode gerar problemas futuros dentro da sociedade.

A relação entre o mapa como instrumento pedagógico de ensino e o educando, torna-se essencial, porque para compreender o conteúdo geográfico esse contato é imprescindível, seja na representação através do reconhecimento do espaço geográfico, desenvolvido a partir do trabalho de campo ou apenas utilizando-o como ferramenta auxiliar na resolução de atividades escolares.

\section{O PAPEL DO MAPA NA GEOGRAFIA}

A ciência geográfica tem como objetivo principal analisar e descrever e/ou representar os acontecimentos da superfície terrestre. Para tanto, utiliza-se de diversos meios com base na representação do fenômeno a ser estudado e representado, tendo como principal instrumento de representação, o mapa.

O homem sempre sentiu necessidade de se localizar na superfície terrestre, de conhecer o mundo, sua diversidade e riquezas, para tanto, recorreu as mais

$\mathrm{RC}: 88698$

Disponível em: https://www.nucleodoconhecimento.com.br/educacao/aprendizagem- 
diversas formas de representação para que pudesse entender melhor os fenômenos e administrar os recursos naturais, dessa forma, produzir espaço geográfico. De alguma maneira, com o passar do tempo, esse interesse o motivou a representar as características de alguns aspectos naturais e/ou culturais presentes na superfície terrestre, buscando identificar diferentes lugares, sempre registrando o que observava.

A necessidade de compreender cada vez mais o que observava, não demorou muito para o homem descobrir a importância do conhecimento do espaço e construir diferentes maneiras de representações gráficas. Primeiro em argila, posteriormente em conchas e fios naturais, pergaminho e por fim, no papel.

Segundo Fitz (2008), a palavra mapa, provavelmente seja cartaginesa, com significado de "toalha de mesa", de acordo com relatos de que tenha surgido a partir de comerciantes que sobre a toalha das mesas desenhavam rotas comerciais. Com o passar do tempo diversas terminologias foram surgindo para designar mapas, no entanto, mapa é uma representação gráfica, em geral em uma superfície plana e numa determinada escala, com a representação de acidentes físicos e culturais da superfície da Terra, de um planeta ou satélite.

Como pode ser observado, o mapa é de suma importância para representação da superfície terrestre ou de parte dela, podendo ser classificado de acordo com o fenômeno representado e qual a sua utilidade. Nesse sentido, existem vários tipos de mapas e sua importância depende dos objetivos e podem ser classificados em: mapas genéricos ou gerais, mapas especiais ou técnicos, mapas temáticos, mapa ou carta imagem. Além disso, de acordo com a escala ainda podem ser classificados como planta, carta cadastral, carta topográfica, carta geográfica.

Segundo Almeida (2010), por ser um instrumento de comunicação, o mapa é utilizado por vários profissionais, no entanto, os geógrafos são provavelmente, os responsáveis desde muito tempo pela criação, produção e interpretação do mapa. E

$\mathrm{RC}: 88698$

Disponível em: https://www.nucleodoconhecimento.com.br/educacao/aprendizagem- 
reafirma essa importância ao comentar que "os mapas constituem, sem dúvida, um dos mais valiosos recursos do professor de Geografia”. (ALMEIDA, 2010, p. 18-19).

Entretanto, qualquer pessoa pode interpretar o mapa, mas é necessário recorrer a linguagem cartográfica convencionada de acordo com a terminologia especifica da Cartografia, ou seja, as normas cartográficas devem ser seguidas para abordar determinado tema ou conteúdo do mapa. A exemplo, os rios que devem ser representados por linhas de cor azul, assim como os aeroportos que são representados por uma figura de um avião. E, o professor principalmente, deve ter esse conhecimento para que seja assimilado também pelo aluno. Para tornar a leitura do mapa mais eficiente é necessário recorrer a simbologia especifica da linguagem cartográfica, pois a especificidade retratada através de códigos e símbolos torna o mapa um instrumento complexo, caso o leitor não tenha esse conhecimento.

Para Simielli (2018) Fundamentalmente, isso nos leva a inferir a importância da criação de uma linguagem própria, que seja eficiente, portanto, uma linguagem cartográfica para que o mapa possa atingir seus objetivos. Além disso, "a Cartografia é considerada, uma linguagem universal e que auxilia na compreensão dos conteúdos geográficos, tais como: o espaço, território, lugar, região e paisagem". (SILVA In SANTOS, 2015, p. 75)

Castrogiovanni (2017), ao mencionar sobre a cartografia, destaca a importância de seu uso científico em Geografia e em outras ciências, oferecendo condições de compreensão espacial do fenômeno a ser estudado, tanto no cotidiano quanto para o cientifico. No entanto, até o século VIII, a Cartografia era vista apenas como uma ferramenta, um conhecimento que tinha como objetivo dominar a técnica de produzir mapas através de regras.

Castellar (2018), menciona sobre a função prática da cartografia, que antes de tudo, serve como instrumento de conhecimento, domínio e controle de um território.

$\mathrm{RC}: 88698$

Disponível em: https://www.nucleodoconhecimento.com.br/educacao/aprendizagem- 
Portanto, interpretar um mapa exige um conhecimento de sua elaboração, sua confecção e decodificação.

Por ser um instrumento de orientação, os mapas são utilizados por pessoas de diferentes áreas e de acordo com seu objeto de estudo. Dessa, forma, antes de tudo para ser um leitor, é necessário se um produtor de mapas. O aluno deve confeccionar o mapa, utilizando a simbologia adequada para depois decodificá-lo, ou seja, para ser leitor é preciso ser mapeador. (CASTRGIOVANNI, 2017).

A Cartografia desenvolveu os mapas especiais, nos quais os objetivos específicos são determinados de acordo com o tema a ser tratado, geralmente utilizado por uma determinada categoria de profissionais ou ainda os mapas gerais, que tratam de temas variados, (MARTINELLI, 2017)

Entre tantos tipos de mapas, os temáticos são bastante utilizados pela Geografia, por serem elaborados para tratar de um tema específico, como exemplo, os mapas demográficos que representam as características da população de um determinado país, região, estado, etc. Podendo também destacar as reservas indígenas de um determinado estado, características geográficas, geopolítica mundial, entre outros temas abordados para o entendimento do conteúdo geográfico.

Para Martinelli (2017), os mapas temáticos são bastante utilizados no Ensino Fundamental e Médio, mas por se tratar de uma maior complexidade, é necessário que nessa fase o educando já tenha um conhecimento da cartografia em termos gerais, ou seja, já possui o domínio da linguagem cartográfica.

A criança é levada ao imaginário, quando motivada ao entendimento do conteúdo através do mapa, além disso, ela pode construir seu próprio mapa, pois existem ainda os mapas mentais, idealizados em nossa mente e podem ser representados através de símbolos não convencionais. "Para compreender um mapa como reprodução do real, é preciso entender sua realidade e sua linguagem. O mapa

$\mathrm{RC}: 88698$

Disponível em: https://www.nucleodoconhecimento.com.br/educacao/aprendizagem- 
mental é o início desse percurso metodológico, permitindo o estudo do lugar de vivência e auxiliando na leitura de um mapa". (CASTELLAR In ALMEIDA, 2018, p. 130).

Os mapas mentais possuem a capacidade de desenvolver no aluno a concepção de espaço ou de mundo que a criança possui podendo também, da sua maneira, utilizando-se da imaginação, representá-lo. No entanto, é necessário que o professor tenha conhecimento que, os mapas representados nos livros didáticos são caracteristicamente diferentes e estas peculiaridades precisam ser identificadas e compreendidas para que possam, de forma correta e adequada, trabalhar com seus alunos. (SILVA, 2015).

Para ler os mapas disponíveis como recurso didático nas escolas, o professor precisa ter conhecimento dos tipos de mapas, o conteúdo representado, os símbolos que devem ser abordados durante a leitura, e o objetivo pelo qual o aluno deve decodificá-lo. (CASTELLAR, 2018).

Neste sentido, ressaltamos a importância da formação do professor para desenvolver importante tarefa, pois ter apenas o domínio do conteúdo geográfico não é suficiente. É necessário um conhecimento adequado da linguagem cartográfica. O domínio dos conceitos pertinentes à Geografia é indispensável, no entanto, o conteúdo cartográfico complementa esse aprendizado, pois na ausência deste, dificilmente o professor, pautado no mapa como auxiliar na aprendizagem do conteúdo geográfico, poderá auxiliar o educando a construir conhecimento.

O mapa tem sido um importante aliado do professor de Geografia no ensino desta ciência, principalmente no Ensino Fundamental, em especial no $6^{\circ}$ ano. O processo de alfabetização cartográfica deve ser feito a partir dos primeiros anos escolares do Ensino Fundamental, porque é nessa fase escolar que a criança precisa adquirir noções básicas da linguagem cartográfica, para que tenha sucesso na vida escolar nas séries posteriores. (SIMIELLI, 2018).

$\mathrm{RC}: 88698$

Disponível em: https://www.nucleodoconhecimento.com.br/educacao/aprendizagem- 
Embora, o processo de letramento cartográfico deva iniciar nas séries iniciais e prolongar-se por toda vida escolar, é apenas a partir do quarto ou quinto ano que a criança será capaz de assimilar com maior propriedade a passagem do espaço perceptivo para a representação espacial. (MARTINELLI, 2017).

Geralmente, ao deparar-se com o livro de Geografia, os professores e alunos evidenciam uma maior dificuldade para ensinar e aprender o conhecimento geográfico nas séries iniciais, tornando o ensino e a aprendizagem nas séries seguintes mais complexo e mais prolongado.

De acordo com Fonseca (2016), os conteúdos de Cartografia dispostos no livro didático parecem estar separados em capítulos específicos sobre o tema, entretanto, essa não seria a forma correta, pois não devem estar isolados dos demais conteúdos de Geografia.

Ao mesmo tempo que de alguma forma, por um longo período se criticou a fragmentação da geografia em física e humana, como se não fossem interrelacionadas, também não pode haver fragmentação do conteúdo da Cartografia. Os conteúdos cartográficos não devem estar" esfarelados", separados dos conteúdos específicos do capítulo do qual faz parte. (FONSECA, 2016).

Portanto, o conhecimento da Cartografia é essencial para aprendizagem do conteúdo geográfico, visto que, é através do domínio da linguagem cartográfica que o aluno consegue interpretar o mapa, elemento que deve fazer parte do processo de ensino de Geografia em todos os níveis, em diferentes modalidades e/ou formas de ensino.

Almeida e Passini (2010), corroboram afirmando que ler mapas, significa dominar o sistema de linguagens, específico da cartografia e que preparar o aluno para essa leitura, exige um esforço que deve passar por preocupações metodológicas como a de ensinar a ler e escrever. Nesse caso, todo esse processo de preparação através

RC: 88698

Disponível em: https://www.nucleodoconhecimento.com.br/educacao/aprendizagem- 
de uma organização sistemática, respeitado as fases de aquisição do aluno, constitui-se a alfabetização cartográfica.

Segundo Almeida (2010), o mapa é um importante recurso visual e o professor deve utilizá-lo para ensinar o conteúdo geográfico. Por ser uma forma de comunicação e, no caso específico do ensino de Geografia precisa ser explorado por professores desta área de ensino.

Além disso, a Geografia é uma ciência que se preocupa com a organização do espaço, desta forma, o mapa é indispensável tanto para investigação quanto para organização de seus dados.

De acordo com Castellar (2018), é necessário inferir que, além da representação espacial, há uma certa aproximação entre o que de fato é realidade e o que está sendo representado no mapa, tornando a representação o mais próximo possível do cotidiano do aluno.

A partir da visualização, identifica-se os elementos da simbologia cartográfica, os fenômenos representados de forma gráfica, bem como, os elementos fundamentais presentes no mapa, sendo possível, a partir de então, conhecer a realidade retratada.

Ao realizar a leitura de um mapa é possível fazer uma análise do lugar de vivência, da sala de aula, do entorno da escola, da casa onde vive, do bairro, do município e até mesmo do estado, país ou lugares muito distantes, ou seja, partir do local para o global em diferentes escalas e conexões. Além de conhecer diferentes realidades geográficas como condições climáticas, formações vegetais, características da população, conflitos territoriais, entre outros, que compõem o conteúdo do currículo escolar e, posteriormente, auxiliará na resolução de atividades ligadas ao convívio social como orientação e localização. (ROMANO, 2017)

$\mathrm{RC}: 88698$

Disponível em: https://www.nucleodoconhecimento.com.br/educacao/aprendizagem- 
A utilização do mapa como recurso didático para o ensino de Geografia é uma maneira de aproximar o entendimento da realidade e dessa forma, desenvolver o raciocínio geográfico, considerando, no ato da leitura, os elementos indispensáveis para seu entendimento. Estes devem seguir as normas cartográficas, estarem organizados de acordo com os padrões normativos e atualizados.

Para ser entendido é necessário que o mapa tenha os elementos indispensáveis à sua leitura como o título; as convenções utilizadas; a base de origem; as referências (autoria e data); a indicação da direção norte, nesse caso, se não houver a existência de um sistema de coordenadas geográficas; a escala; o sistema de projeção utilizado e o sistema(s) de coordenada(s) utilizado. (CASTROGIOVANNI, (2017).

O mapa possui uma linguagem codificada, porém cada leitor tem sua maneira especifica de decodificá-lo, por isso a linguagem cartográfica é universalmente padronizada ou convencionada. Não devendo, portanto, estar fora dos padrões em nenhuma situação. Cabe a Cartografia padronizar a simbologia, possibilitando ao leitor de quaisquer lugares do Planeta sua leitura e compreensão, apropriar-se desse conhecimento e utilizá-lo em seu cotidiano.

Se o usuário do mapa tiver domínio da linguagem cartográfica convencionada, consegue realizar a leitura e compreender o mapa em sua real função ou objetivo ao qual se destina, podendo ainda, como já foi assinalado, fazer uma leitura crítica e transpor suas informações para o uso no cotidiano.

Portanto,

O aluno precisa ser preparado para "ler" representações cartográficas: Só lê mapas quem aprendeu a construí-los. A cartografia, originalmente, é um instrumento usado para organizar a vida do cotidiano, no entanto, tornou-se uma técnica para dominação dos territórios e das populações. (CASTRGIOVANNI, 2017, p. 35, grifo do autor).

RC: 88698

Disponível em: https://www.nucleodoconhecimento.com.br/educacao/aprendizagem- 
Em outras palavras, o conhecimento da linguagem cartográfica possibilita ao leitor a percepção e compreensão de determinada simbologia representada no mapa que Ihe será útil. A exemplo, para uma pessoa que domina a linguagem cartográfica e que pretende saber a localização dos aeroportos de uma cidade que ela não conhece.

Nesse caso, ao observar o desenho de um avião em um mapa desta mesma cidade, terá conhecimento dos pontos ou localização dos aeroportos e com esta informação, poderá inferir que a figura de um avião está, neste caso, representando este ponto. Este é apenas uma, entre outras utilidades, que o mapa pode proporcionar para a vida em sociedade, portanto, o professor precisa utilizar-se deste instrumento para melhor desempenhar o aprendizado dos alunos, consequentemente, a vida em sociedade.

Para o estudo do mapa deve ser considerado também a atualização dos fatos ou dados, ou seja, um mapa não pode ser desatualizado em relação ao fenômeno estudado, pois o aluno poderá inferir outra realidade, o que de fato, poderá prejudicá-lo. No entanto, é necessário acrescentar que este é o papel do professor, estar sempre preocupado em consultar fontes confiáveis e atualizadas, pois as mudanças ocorridas no espaço geográfico influenciam na resolução de problemas, sejam eles sociais, ambientais, políticos, econômicos, entre outros assuntos abordados em Geografia.

As mudanças do espaço são dinâmicas e os fenômenos ocorridos devem ser estudados de acordo com a realidade dos fatos, proporcionando ao professor um melhor desempenho em sua prática, possibilitando também ao aluno uma melhor compreensão e atuação na realidade de forma crítica e significativa.

O professor poderá também comparar distintas realidades, de forma que motive o aluno ao entendimento da transformação do espaço através de ações humanas ou naturais. Isso é possível através de mapas temáticos, podendo ser comparados de

$\mathrm{RC}: 88698$

Disponível em: https://www.nucleodoconhecimento.com.br/educacao/aprendizagem- 
acordo com diferentes fenômenos, escalas e conexões os quais o professor pretende explicar.

Os mapas temáticos são muito utilizados no ensino de Geografia, pois trata de temas específicos, abordando conjuntamente um mesmo território, porque na sua multiplicidade, muitas vezes, são considerados como da Geografia, ao mesmo tempo em que o geógrafo é tido como especialista mais competente para essa tarefa, (MARTINELLI, 2016).

Ao abordar sobre especificidade, os mapas temáticos são bastante utilizados pelos professores, pois interessam ao estudo e compreensão de temas específicos relacionados a determinado conteúdo geográfico. Nesse sentido, ao retratar determinado fenômeno espacial, deve fazê-lo de forma específica, abordando características próprias, com dados consistentes, atuais e, sobretudo da realidade próxima ao estudante. Ao considerar tais pressupostos, o professor viabilizará ao aluno um contínuo aprendizado, pautado na realidade que o cerca, resultando na resolução de questões a ele propostas, auxiliando-o na busca de conhecimento.

Portanto, os mapas não seriam vistos como tradicionalmente é feito, como meras figuras ilustrativas dos textos didáticos, mas como representações reveladoras de questões que serão abordadas e discutidas nos discursos geográficos, dando chance a uma reflexão crítica e consciente entre os estudantes, orientada pelo mestre em sala de aula. (MARTINELLI, 2018, p. 59).

Os mapas temáticos também precisam abordar as relações entre as atividades humanas e o fenômeno retratado, promovendo um melhor entendimento para o leitor. Nesse sentido, possibilitará ao aluno a compreensão de que a pluralidade dos mapas temáticos pode descrever um mesmo território de várias maneiras, sendo considerados diferentes aspectos.

A exemplo o território brasileiro e suas múltiplas representações, como diversidade climática, formações vegetais, características da população, aspecto político, divisão regional, entre outros temas de grande relevância para o estudo e compreensão do

RC: 88698

Disponível em: https://www.nucleodoconhecimento.com.br/educacao/aprendizagem- 
espaço geográfico, seja este nacional, estadual, municipal ou quaisquer representações de interesse para aprendizagem do conteúdo da Geografia.

Essa diversidade de informações está disponível de forma gráfica nos livros didáticos, como também, em outras formas de representações e podem ser encontradas com facilidade atualmente. $\mathrm{E}$, por estarem mais acessíveis, têm sido de grande relevância para o trabalho do professor e demais profissionais que precisam de um instrumento de orientação para se localizarem ou localizarem um determinado ponto de interesse. (MARTINELLI, 2018).

Embora sendo de interesses diversos, o mapa sempre servirá de apoio para as sociedades atuais, de modo que o saber geográfico adquirido ao longo de anos e posto em prática por determinados interesses, indiscutivelmente, terá uma finalidade para a humanidade.

\section{O MAPA E O ENSINO REMOTO}

Em virtude da pandemia da COVID-19 os professores e alunos foram impossibilitados de desenvolver atividades educacionais que envolvesse o contato físico no espaço escolar. Diante desse cenário de isolamento social e a impossibilidade de práticas educativas presenciais, foi necessário repensar a maneira de ensinar e os instrumentos a serem utilizados.

Com isso, a aplicação do ensino remoto através das tecnologias educacionais foi medida decisiva e significativa para dar continuidade ao processo educativo. Desta forma, para acontecer a integração entre a comunidade escolar, professores se dedicaram ao aprendizado em relação ao uso de diversos programas e aplicativos disponíveis, para que pudessem desenvolver seu trabalho com o aluno de forma significativa.

RC: 88698

Disponível em: https://www.nucleodoconhecimento.com.br/educacao/aprendizagem- 
Muitas ferramentas foram indispensáveis para esse acontecimento e o uso de aplicativos e endereços eletrônicos, como WhatsApp, zoom, google Meet, Youtube, Facebook, e-mails, entre outros, foram bastante utilizados para desenvolver aulas.

As redes sociais já eram utilizadas por grande parte da população mundial, mas poucos com esse objetivo. Entretanto, o aumento em relação ao uso dos instrumentos tecnológicos no ensino deu-se em função da pandemia do coronavírus. O uso das tecnologias da informação para aprendizagem do aluno é de grande aproveitamento, assim como, para capacitação de professores de diversas áreas.

Para professores de Geografia, as ferramentas tecnológicas têm sido aliadas incondicionais, pois além de possibilitar a comunicação e aproximar as pessoas por conta do isolamento social, professores e alunos também aprendem e/ou aperfeiçoam novas maneiras de construir conhecimento. Entretanto, apesar do constante aprendizado quanto ao uso das ferramentas, as dificuldades ainda persistem e são observadas ao trabalhar com mapas, pois além dos conteúdos conceituais, é necessário que o professor domine também metodologias adequadas para o ensino do conteúdo cartográfico.

Dessa forma, é fundamental, "Compreender qual é o conteúdo mais adequado, que mais sentido tem hoje para um trabalho escolar em Geografia, que possibilita e estimula o tratamento da diversidade dos alunos, é de fato um avanço nas práticas de ensino". (CAVALCANTI, 2017, p. 77).

Neste sentido, ao buscar novos métodos educacionais, o educador deve fazer uma autoavaliação, para que possa inferir sobre a própria ação, sua metodologia, as questões éticas e as consequências políticas de método de ensino para condução dos alunos a uma reflexão de forma crítica, (CARVALHO; PONTE; SILVA, 2015).

RC: 88698

Disponível em: https://www.nucleodoconhecimento.com.br/educacao/aprendizagem- 
Trabalhar com mapa de forma remota, além de exigir o domínio da linguagem específica para sua decodificação, é necessário dominar também metodologias adequadas para esse aprendizado.

Guerreiro (2017), alerta para a necessidade de o professor de Geografia buscar novas metodologias além do domínio do conteúdo específico e técnicas didáticopedagógicas, como também o uso de elementos espaciais (rua, bairro, em que os alunos moram, etc.) e também as representações gráficas. E destas tendo pleno domínio.

Não restam dúvidas de que o mapa é importante para o estudo de Geografia e, que deve estar presente no ensino geográfico, seja presencial ou a distância. O educando precisa ter contato com o mapa e dominar sua linguagem, de forma que consiga associar seu conteúdo com a simbologia representada.

As ferramentas tecnológicas devem ser consideradas nesta perspectiva de ensino, pois além de disponibilizar programas e recursos para o estudo do mapa, auxiliam o aprendizado através de modernos instrumentos. (FILHO e GENGNAGEL, 2020).

A exemplo, o celular e o computador, que disponibilizam softwares gratuitos que permitem ao aluno navegar por imagens diversas de sensores remotos, com variadas resoluções em tempo real, de acordo com o momento da coleta de imagens. (CARVALHO; PONTE; SILVA, 2015).

De acordo com o pressuposto, o mapa, pode ser um instrumento metodológico de grande importância para o processo de ensino e aprendizagem dos conteúdos geográficos, tornando o conhecimento mais significativo para vida em sociedade.

A importância do mapa não deve ser descartada ao falar de ensino remoto de Geografia, no entanto,

RC: 88698

Disponível em: https://www.nucleodoconhecimento.com.br/educacao/aprendizagemde-geografia 
É necessário enfatizar que existem diversos objetos, metodologias e programas direcionados à otimização das práticas de ensino, não somente geografia, mas de outras disciplinas escolares que, por meio da leitura dos mapas, atraem cada vez mais os alunos a aprender praticando em ambiente computacional, saindo do ambiente "estático" oferecido pelos livros didáticos. (CARVALHO; PONTE; SILVA, 2015, p. 73, grifo dos autores).

Nas últimas décadas surgira muitos programas e aplicativos voltados para o ensino virtual. Esses programas voltados para o mapeamento online têm sido de muita importância para os professores no ensino de Geografia. (CANTO; ALMEIDA, 2018).

A tecnologia desenvolvida pela cartografia digital disponibiliza, entre outros programas, o Google Maps e o google classroom, ferramentas gratuitas e inovadora que possuem um acervo de imagens georreferenciadas por satélite, possibilitando a emergência de localização e da prática cartográfica. Embora, sendo de forma virtual ou impresso, o mapa deve ter alguns elementos importantes que precisam ser considerados ao trabalhar a leitura e interpretação. Evidenciados de forma clara e objetiva, seguindo as normas da Cartografia.

No caso dos mapas digitais, todos os elementos fundamentais para sua interpretação devem estar presentes, pois as técnicas utilizadas para elaboração através de geoprocessamento utilizam todos os detalhes e devem estar claramente estabelecidas no mapa.

Outro meio de igual relevância para o ensino de mapas de forma remota é o Sensoriamento Remoto. Assim como Carvalho; Ponte e Silva (2015), outros autores defendem a importância do uso de mapas virtuais como recurso didático para o ensino de Geografia, como observa-se nas ideias de Ramos e Chaves,

Produtos do Sensoriamento Remoto como imagens de satélite e fotografias aéreas pode ter grande potencial como recurso didático na sala de aula. Por meio das imagens de satélite pode se trabalhar diversos conteúdos relacionados a questões ambientais que são do âmbito tanto das disciplinas de Geografia, como das Ciências e/ou Biologia.

$\mathrm{RC}: 88698$

Disponível em: https://www.nucleodoconhecimento.com.br/educacao/aprendizagem- 
Assim, o Sensoriamento Remoto promove também a interdisciplinaridade que potencializa ainda mais o seu uso escolar. (RAMOS e CHAVES, 2017, p. 2).

É necessário, porém, que o professor ao fazer uso deste importante recurso pedagógico, tenha domínio para que possa realizar a mediação deste com 0 conteúdo em sala de aula, favorecendo aos alunos uma melhor aprendizagem.

O uso das tecnologias em aulas remotas contribui também para fomentar a participação dos alunos, pois apenas textos com orientações metodológicas de como realizar as atividades não desperta o interesse do estudante. (FILHO e GENGNAGEL, 2020).

É necessário inovar as práticas, buscar novos métodos. O ensino do mapa utilizando os aplicativos é uma maneira de desenvolver atividades de forma motivadora. $O$ docente tem a possibilidade de realizar várias atividades através dos aplicativos e/ou plataformas digitais, pois podem também assistir e gravar aulas, além de promover encontros com a turma para esclarecer possíveis dúvidas sobre o assunto.

O uso do mapa virtual em aulas remotas é uma estratégia significativa, pois além de despertar o interesse do aluno, também auxilia no entendimento do conteúdo geográfico. Ressalta-se, no entanto, que muitos alunos ainda estão à margem da globalização virtual, como afirma Filho e Gengnagel,

Estes alunos fazem parta dos "excluídos" da Globalização e do ciberespaço, escancarada de forma brutal em tempos da COVID-19. Neste sentido, cabe a nós professores e a equipe gestora promover outros meios para esses alunos terem acesso ao material de trabalho para a continuidade dos seus estudos. (FILHO e GENGNAGEL, 2020, p. 92).

O professor deve possibilitar o acesso desses alunos ao material de forma impressa, embora não seja uma prática constante, muitos educandos não são motivados a realizar as atividades, pois as orientações contidas nos roteiros de estudo não despertam interesse aos mesmos.

$\mathrm{RC}: 88698$

Disponível em: https://www.nucleodoconhecimento.com.br/educacao/aprendizagem- 
A qualidade do mapa elaborado em sistemas virtuais, deve ser a mesma em relação aos mapas impressos. No entanto, existem algumas considerações a esse respeito, pois uma das vantagens do mapa virtual é ter alta qualidade e dados atualizados, possibilitando ao serem compreendidos, um aprendizado em tempo real.

O professor tem várias possibilidades para utilizar o mapa, por exemplo, os mapas digitais que abordem diferentes características geográficas como relevo, hidrografia, clima, distribuição da população, regionalização, entre outros temas, que envolvem a aprendizagem de Geografia. Através do computador ou celular, o aluno tem acesso a diferentes aplicativos que direcionam a vários tipos de mapas, podendo ler, interpretar e produzir.

Um aplicativo que contribui de forma significativa para realização de aulas remotas é - WhatsApp. Seu desempenho foi bastante evidenciado como ferramenta educacional, pois é gratuito e acessível ao professor e ao aluno, entretanto, precisa estar conectado à internet.

Através do celular, os mapas podem ser enviados para o aluno em forma de Quiz, disponibilizados na internet. Esses jogos levam o aluno a uma forma divertida de aprender. Entretanto, os jogos geográficos servem apenas para testar conhecimentos em Geografia. Nestes jogos, o aluno é direcionado ao mundo virtual e a uma forma prazerosa de entender algumas informações básicas e ter contato com o mapa.

Atividades desenvolvidas de forma remota enriqueceram o ensino de várias áreas do conhecimento, no caso da Geografia, através do zoom e do google Meet, o professor pode apresentar o mapa em slides acompanhado do conteúdo de interesse ao qual propõe o aprendizado.

Outro ponto relevante dessa discussão é a necessidade dos docentes se adaptarem as novas metodologias desenvolvidas através do uso de instrumentos

RC: 88698

Disponível em: https://www.nucleodoconhecimento.com.br/educacao/aprendizagem- 
tecnológicos. Destaca-se também, a importância do planejamento, dos procedimentos de ensino e da avaliação da aprendizagem. (FILHO e GENGNAGEL, 2020).

Trabalhar com mapas através de aulas remotas e utilizando instrumentos tecnológicos de forma satisfatória, ainda está longe da realidade de muitos, pois além das questões didático-pedagógicas, as condições de trabalho docente também são precárias No entanto, assim como já houve mudanças em relação a pandemia, novas adaptações serão feitas quanto a prática pedagógica e ao modelo de gestão educacional.

É necessário novos olhares para educação brasileira, visando o desenvolvimento de cidadãos críticos e participativos. Nesse sentido, o ensino híbrido tem sido uma alternativa bastante discutida entre a maioria dos educadores, no sentido de amenizar os déficits educacionais causados pelo distanciamento.

No entanto, a presença dos educandos nas escolas é mais um desafio para o processo educativo, pois é necessário fazer um cronograma de atendimento alternado para contemplar todas as necessidades educacionais e proteger a comunidade escolar da COVID-19.

Porém, é necessário deixar claro que o ensino do mapa, independente da modalidade e do contexto social no qual o aluno está inserido, deve ser desenvolvido para que contemple o desenvolvimento do educando de forma integral. A prática educativa deve ser pautada em um ensino crítico que tenha relevância social.

\section{CONSIDERAÇÕES FINAIS}

Verificou-se com este estudo que, o uso do mapa no ensino de Geografia é de grande relevância, pois trata-se de um recurso indispensável ao professor, pois

$\mathrm{RC}: 88698$

Disponível em: https://www.nucleodoconhecimento.com.br/educacao/aprendizagem- 
independente da modalidade de ensino, a aprendizagem só acontece se o aluno interpretar o mapa, entretanto este processo só ocorre se ele tiver domínio da linguagem cartográfica.

Por se tratar de um importante instrumento de aprendizagem, o mapa deve ser incluído no processo de aprendizagem desde as séries iniciais através da alfabetização cartográfica, uma vez que, sua leitura e interpretação é bastante significativa, pois sua aprendizagem irá prolongar-se por toda vida, enquanto recurso didático e em seu cotidiano.

Ao utilizar o mapa, o professor deve ter conhecimento de sua simbologia, seus elementos, a fim de que, esta ferramenta seja útil para o aluno e possa contribuir para o entendimento do conteúdo geográfico, por conseguinte, da resolução de problemas do seu cotidiano.

Através desse estudo conclui-se que, além dos mapas impressos, os virtuais também fazem parte do cotidiano escolar, pois através da tecnologia, o professor pode utilizá-lo dentro da sala de aula de forma remota. E ao contar com diferentes meios de realizar a aula e em tempo real, o professor também pode torná-la prazerosa. Nesse sentido, esses instrumentos tornam-se indispensáveis para análise e compreensão do espaço geográfico.

Durante as leituras, vários aspectos foram observados e considerados como facilitadores em relação ao ensino de Geografia de forma remota. e ficou evidente que sem a utilização do mapa, não ocorre o entendimento do conteúdo geográfico, pois é parte integrante do processo.

O estudo mostrou também, de um modo geral, que ao empregar diferentes ferramentas de ensino em sua prática, o professor motiva os alunos a participarem da aula, aguçando a curiosidade e melhorando o desempenho quanto a aquisição de conhecimentos.

RC: 88698

Disponível em: https://www.nucleodoconhecimento.com.br/educacao/aprendizagem- 
Além disso, a Geografia é a disciplina que mais utiliza mapa em sala de aula, portanto, caso o professor não o utilize por não compreender a linguagem cartográfica ou por qualquer outro motivo, pode causar consequências posteriores na vida do educando e sua convivência em sociedade. E para que o aprendizado do conteúdo geográfico realmente aconteça, o contato com o mapa se torna indispensável, pois ao lidar com informações cartográficas e interpretá-las corretamente, o aluno compreenderá o conteúdo proposto.

Enfim, é preciso possibilitar ao aluno a construção do conhecimento geográfico em sala de aula para que este desenvolva a capacidade de análise, leitura e compreensão, atuando de forma significativa no mundo em que ele está inserido, sobretudo diante de um contexto tão complexo quanto o período de isolamento social vivido no momento.

Desta forma, este trabalho abre a possibilidade de futuras discussões acerca do tema aqui proposto, considerando que através da discussão e do diálogo é possível entender e acreditar em possíveis intervenções significativas para melhorias na educação brasileira e no ensino de geografia na educação básica.

\section{REFERÊNCIAS}

ALMEIDA, R. D. (Org.). Cartografia escolar. 2. ed. São Paulo: Contexto, 2010.

A Cartografia e a construção do conhecimento em contexto escolar In: ALMEIDA, R D. (Org.) Novos rumos da cartografia escolar: currículo, linguagem e tecnologia. 1. ed. São Paulo: Contexto, 2018.p. 121-136

Novos rumos da cartografia escolar: currículo, linguagem e tecnologia. 1. ed. São Paulo: Contexto, 2018.

ALMEIDA R.D; PASSINI, E. Y. O Espaço geográfico: ensino e representação. 15. ed. São Paulo: Contexto, 2010.

$\mathrm{RC}: 88698$

Disponível em: https://www.nucleodoconhecimento.com.br/educacao/aprendizagemde-geografia 
BRASIL. Base Nacional Comum Curricular. Brasília: MEC, 2017 Brasília: Disponível em http://basenacionalcomum.mec.gov.br/ Acesso em: dez de 2020.

CANTO, Tânia S. Mapas feitos por não cartógrafos e a prática cartográfica no ciberespaço In: ALMEIDA. R.D (Org.). Novos rumos da cartografia escolar: currículo, linguagem e tecnologia. 1. ed. São Paulo: Contexto, 2018, p. 147-162.

CASTELLAR, Sonia (Org.) Educação Geográfica: teorias e práticas docentes. 3. ed. São Paulo: Contexto, 2017.

CASTROGIOVANI, A; CALLAI, Helena C; KAERCHER, N. André. Ensino de Geografia: Práticas e textualizações no cotidiano. Porto Alegre: Artmed, 2017.

CAVALCANTI, Lana de Sousa. Ensino de Geografia e diversidade: Construção de conhecimento geográficos escolares e atribuição de significados pelos diversos sujeitos do processo de ensino In: CASTELLAR, Sonia (Org.) Educação Geográfica: teorias e práticas docentes. 3. ed. São Paulo: Contexto, 2017.p. 6678

FITZ, Paulo Roberto. Cartografia básica. São Paulo: Oficina de Textos, 2008.

FONSECA, Eugênio P. Cartografia escolar: a cartografia da sala de aula. 1.ed. São Paulo: Boreal Edições, 2016.

FONSECA, Fernanda P; OLIVA, Jaime Tadeu. A Geografia e suas linguagens: o caso da Cartografia. In: CARLOS, A. F. A. (org.). A Geografia na sala de aula. 8. ed. São Paulo: Contexto, 2018. p. 62-78.

FILHO, Odair Ribeiro de C; GENGNAGEL, Claudionei L. Ensino de geografia em tempos da covid-19: tecnologias e uso de plataformas de educação para o ensino remoto em Ribeirão Preto/SP e em Passo Fundo/RS. Revista Ensaios de Geografia, Niterói, vol. 5, no 10, p. 88-94, julho de 2020. Disponível em:

RC: 88698

Disponível em: https://www.nucleodoconhecimento.com.br/educacao/aprendizagemde-geografia 
https://periodicos.uff.br/ensaios_posgeo/article/view/42343/pdf.

Acesso

em 14/02/2021.

GUERREIRO, Ana L. Araújo. Alfabetização e letramento cartográficos na geografia escolar. São Paulo: Edições SM, 2012.

GUERREIRO, Ana L. Araújo. Contribuições da teoria da atividade para formação continuada de professores de Geografia In: CASTELLAR, Sonia (Org.) Educação Geográfica: teorias e práticas docentes. 3. ed. São Paulo: Contexto, 2017.

MARTINELLI, M. Atlas geográficos para escolares: uma revisão metodológica In: ALMEIDA. R.D (Org.). Novos rumos da cartografia escolar: currículo, linguagem e tecnologia. 1. ed. São Paulo: Contexto, 2018, p. 57-60.

MARTINELLI, M. mapas da geografia e cartografia temática. 6. ed. São Paulo: Contexto, 2016.

MARTINELLI, M. O ensino da cartografia temática In: CASTELLAR, Sonia (Org.) Educação Geográfica: teorias e práticas docentes. 3. ed. São Paulo: Contexto, 2017.p. 51-65.

PIMENTEL, Junívio; ROCHA, Gabriela S.; COSTA, Clauber B. As linguagens e o ensino de geografia. In: PIMENTEL, Junívio; ROCHA, Gabriela S.; COSTA, Clauber B. Pesquisas e Práticas no Ensino de Geografia. 1ed.Curitiba: Appris, 2016. P.8991.

RAMOS, Ana Paula; CHAVES, M.J. Potencial pedagógico do sensoriamento remoto como recurso didático no ensino de geografia. Boletim Gaúcho de geografia v. 44, no 1/2, 2017, p.138-154. Disponível em: https://seer.ufrgs.br/bgg/article/view/59075/49416. Acesso em: 22/01/2021.

RC: 88698

Disponível em: https://www.nucleodoconhecimento.com.br/educacao/aprendizagemde-geografia 
ROMANO, Sonia. M. M. Alfabetização cartográfica: a construção do conhecimento de visão vertical e a formação de professores in: CASTELLAR, Sonia (Org.) Educação Geográfica: teorias e práticas docentes. 3. ed. São Paulo: Contexto, 2017.p. 157-167.

SILVA, Christian N.; CARVALHO, João dos S.; PONTE, Franciney C. da. Elementos de cartografia para o ensino do espaço geográfico. 1. ed. Belém: GAPTA/UFPA, 2015.

SILVA, Marilza dos. Os processos abstratos e a representação do espaço feito por indivíduos com autismo In: SANTOS, Clézio (Org,). Cartografia geográfica e representação gráfica. Nova Iguaçu: Agbook, 2015.

SIMIELLI, Maria Elena. Cartografia no ensino fundamental e médio. In: CARLOS, A. F. A geografia na sala de aula. 8. ed. São Paulo: Contexto, 2018. p.92-108.

Enviado: Março, 2021.

Aprovado: Junho, 2021.

RC: 88698

Disponível em: https://www.nucleodoconhecimento.com.br/educacao/aprendizagemde-geografia 